\title{
A study on prevalence of alcohol consumption among higher secondary school students in Theni district, Tamil Nadu
}

\author{
Shankareswari S. ${ }^{1}$, Jayapriya B. ${ }^{2 *}$, Sandeep K. ${ }^{3}$, Lourdu Jafrin A. ${ }^{4}$
}

\author{
${ }^{1}$ Department of Pharmacology, Government Medical College and Hospital, Karur, Tamil Nadu, India \\ ${ }^{2}$ Department of Pharmacology, Thanjavur Medical College, Thanjavur, Tamil Nadu, India \\ ${ }^{3}$ Government Theni Medical College, Theni, Tamil Nadu, India \\ ${ }^{4}$ Department of Pharmacology, Indira Gandhi Medical College and Research Institute, Pondicherry, India
}

Received: 02 January 2020

Revised: 17 January 2020

Accepted: 18 January 2020

\author{
*Correspondence: \\ Dr. Jayapriya B., \\ Email: jayapriyabalamurugan@gmail.com
}

Copyright: () the author(s), publisher and licensee Medip Academy. This is an open-access article distributed under the terms of the Creative Commons Attribution Non-Commercial License, which permits unrestricted non-commercial use, distribution, and reproduction in any medium, provided the original work is properly cited.

\begin{abstract}
Background: Studies show that in India, the health loss from alcohol will grow larger, unless effective interventions are implemented. Initiation of alcohol intake starts from a very early age and is higher in rural areas. The best way to reduce alcoholism is prevention rather than curing the already addicted persons. For this we need to know the magnitude of this problem. This study is aimed at estimating the prevalence, identifying the causative and contributing factors of alcoholism among higher secondary school children of Theni district.

Methods: A self-administered validated questionnaire was given to the male school students of 15 to 17 years (XI and XII students) to assess the prevalence and pattern of alcohol use among them. The questionnaire was prepared with reference from the global school-based student health survey (GSHS), the alcohol use disorders identification test (AUDIT) questionnaire and the cut-annoyed-guilty- eye (CAGE) questionnaire. Data analysis was done using software OpenEpi, Version 3.

Results: A total of 500 students were analyzed with a response rate of $94 \%(n=470)$. The overall prevalence of alcohol use was found to be $31.06 \%$. Nearly $70 \%$ had the possibility of alcoholism and should be investigated further for severity of alcohol use, $30 \%$ had impaired control over drinking almost daily and $17 \%$ had injury or injured someone because of drinking.

Conclusions: The mean age of initiation of alcohol consumption is decreasing and the number of alcohol consumers is increasing.
\end{abstract}

Keywords: Prevalence, Alcoholism, School children

\section{INTRODUCTION}

India, a country highly reputed for its culture of abstinence especially regarding matters of alcohol, is now experiencing increasing number of people getting addicted to liquor. Alcohol consumption has led to $5.9 \%$ of premature deaths and $10 \%$ of disease burden globally. ${ }^{1}$ A recent study highlighted that in India, health loss from alcohol will grow even larger, unless effective interventions and policies are implemented to reduce these habits. ${ }^{2}$

Thirty percent of Indian population above 15 years age has the habit of alcohol consumption. Previous studies have focused mainly on alcohol use in college students, but it is also important to know the alcohol use among higher secondary school children since initiation of alcohol intake starts from a very early age and is higher in rural areas. 
The best way to reduce alcoholism is prevention by creating awareness about the ill effects of alcohol consumption among school students, which is more effective than curing the already addicted persons. For this we need to know the magnitude of this problem.

This study is aimed at estimating the prevalence of alcohol consumption among male school students aged 15 to 17 years and also to identify the causative and contributing factors of alcoholism.

\section{METHODS}

\section{Study setting}

The study was done in higher secondary schools in Theni district, Tamil Nadu. Theni district is situated in the south-western part of Tamil Nadu. It is predominantly rural with a large number of people practicing agriculture and daily wage workers.

\section{Study type}

It is a cross-sectional, descriptive study. A selfadministered questionnaire was given to the school students to assess the prevalence of alcohol use among them.

\section{Time frame}

The study was done during the period of two months from August 2016 to September 2016.

\section{Sample size}

500 students across the district, was chosen by random sampling method.

\section{Inclusion criteria}

Male students aged between 15 to 17 years (XI and XII students) were included.

\section{Exclusion criteria}

Female students were excluded from this study.

\section{Data collection}

A pilot study was conducted before the actual study to check the quality of the questionnaire. After obtaining informed consent, a self-administered questionnaire in vernacular language was given to the students. Data collection was conducted in the classrooms, after giving a detailed description about the purpose of the study. To reduce the fear of inhibition due to disclosure of the student's identity, the students were asked not to mention their name or any other personal information.

\section{Study variables}

The questionnaire was prepared with reference from the global school based student Health Survey (GSHS), the alcohol use disorders identification test (AUDIT) questionnaire and the CAGE (cut-annoyed-guilty- eye) questionnaire..$^{3-5}$

\section{Data analysis}

Data analysis was done using software OpenEpi, Version 3. Chi square, mean, percentages and ' $p$ ' values were calculated. A ' $\mathrm{p}$ ' value less than 0.05 is taken to denote significant relationship. A univariate analysis was carried out to test the association between socio-demographic and other associated factors and alcohol use.

\section{RESULTS}

A total of 500 students in the age group of 15 to 17 years were analyzed with a response rate of $94 \%(n=470)$. All the participants were males. The average age of the study participants was $16.26 \pm 0.94$ years.

The overall prevalence of alcohol use was found to be $31.06 \%$. Out of 470, 146 have given the history of alcohol consumption. The prevalence of this study was quite high compared to the results of previous studies which shows the prevalence of $4 \%$ to $9.4 \%$

Nearly $50 \%$ of the study participants had had their first alcoholic drink at the age of 15 to 17 years. For nearly $60 \%$, the place of their first drink was a public place and the most common reason for first drink was any function or festival (Table 1).

Home or hostel, urban or rural, nuclear or joint family, parents' education and occupation, amount of pocket money were not found to be significantly associated with alcohol use on univariate analysis.

Drinking habits of parents, siblings and friends, discussion about the ill effects of alcohol at school or home and tobacco use were found to be significantly associated with alcohol use by univariate analysis (Table 2).

More than half $(57 \%)$ of the study population had a preference for beer and the most usual place of alcohol consumption seems to be public place $(70 \%)$. Forty five percent of students drink alcohol at the frequency of monthly once or less and the usual amount of consumption is 1 or 2 drink per day [ 1 drink=180 $\mathrm{ml}$ ] (Table 3).

Eighty percent of students' company for drinking alcohol is friends and the most usual way (42\%) of getting alcohol is through friends. This explains the role of friends (peer pressure) in developing the habit of alcohol consumption. 
Table 1: Prevalence and contributing factors for first drink.

\begin{tabular}{|lll|}
\hline Factors & Number & Percentage (\%) \\
\hline Have you ever consumed alcohol? & & 31.06 \\
\hline Yes & 146 & 68.93 \\
\hline No & 324 & \\
\hline Age of first drink (years) & & 4.79 \\
\hline$\leq 7$ & 7 & 2.74 \\
\hline $8-10$ & 4 & 12.33 \\
\hline $11-14$ & 18 & 51.37 \\
\hline $15-17$ & 75 & 28.77 \\
\hline$\geq 17$ & 42 & 7.59 \\
\hline Place of first drink & & 19.86 \\
\hline Home & 11 & 2.07 \\
\hline Friends home & 29 & 4.14 \\
\hline Hostel & 3 & 66.43 \\
\hline Bar & 6 & \\
\hline Public place like park & 97 & 10.27 \\
\hline Reason for first drink & & 10.96 \\
\hline Out of own interest & 15 & 15.07 \\
\hline Compulsion by friends & 16 & 61.64 \\
\hline Stress & 22 & 2.04 \\
\hline Festival/ function & 90 & \\
\hline Others (mixed) & 3 & \\
\hline
\end{tabular}

Table 2: Sociodemographic data and associated factors.

\begin{tabular}{|c|c|c|c|}
\hline Associated factors & Total no. of subjects & $\begin{array}{l}\text { No. of subjects with } \\
\text { alcohol use } \mathrm{N}(\%)\end{array}$ & $\chi^{2}, \mathrm{p}$ value \\
\hline \multicolumn{3}{|l|}{ Residence } & \multirow{3}{*}{$\begin{array}{l}0.1619 \\
p>0.05\end{array}$} \\
\hline Home & 442 & $137(30.99)$ & \\
\hline Hostel & 28 & $9(32.14)$ & \\
\hline \multicolumn{3}{|l|}{ Location } & \multirow{3}{*}{$\begin{array}{l}0.095 \\
p>0.05\end{array}$} \\
\hline Urban & 58 & $17(29.31)$ & \\
\hline Rural & 412 & $129(31.31)$ & \\
\hline \multicolumn{3}{|l|}{ Type of family } & \multirow{3}{*}{$\begin{array}{l}1.602 \\
p>0.05\end{array}$} \\
\hline Nuclear & 339 & $111(32.74)$ & \\
\hline Joint & 131 & $35(26.71)$ & \\
\hline \multicolumn{3}{|l|}{ Literacy of father } & \multirow{3}{*}{$\begin{array}{l}0.07931 \\
\mathrm{p}>0.05\end{array}$} \\
\hline Educated & 253 & $80(31.62)$ & \\
\hline Uneducated & 217 & $66(30.41)$ & \\
\hline \multicolumn{3}{|l|}{ Literacy of mother } & \multirow{3}{*}{$\begin{array}{l}0.2692 \\
p>0.05\end{array}$} \\
\hline Educated & 301 & $96(31.89)$ & \\
\hline Uneducated & 169 & $50(29.58)$ & \\
\hline \multicolumn{3}{|c|}{ Employment status of father } & \multirow{3}{*}{$\begin{array}{l}0.07931 \\
p>0.05\end{array}$} \\
\hline Employed & 217 & $66(30.41)$ & \\
\hline Unemployed & 253 & $80(31.62)$ & \\
\hline \multicolumn{3}{|c|}{ Employment status of mother } & \multirow{3}{*}{$\begin{array}{l}0.4361 \\
p>0.05\end{array}$} \\
\hline Employed & 319 & $96(30.09)$ & \\
\hline Unemployed & 151 & $50(33.11)$ & \\
\hline \multicolumn{3}{|c|}{ Pocket money/month in INR } & \multirow{5}{*}{$\begin{array}{l}6.364 \\
p>0.05\end{array}$} \\
\hline$<300$ & 342 & $97(28.36)$ & \\
\hline $300-500$ & 71 & $30(42.25)$ & \\
\hline $500-1000$ & 28 & $11(39.28)$ & \\
\hline$>1000$ & 29 & $8(27.58)$ & \\
\hline
\end{tabular}




\begin{tabular}{|c|c|c|c|}
\hline Associated factors & Total no. of subjects & $\begin{array}{l}\text { No. of subjects with } \\
\text { alcohol use } \mathrm{N}(\%)\end{array}$ & $\chi^{2}, \mathrm{p}$ value \\
\hline \multicolumn{3}{|c|}{ Drinking habit of parents } & \multirow{4}{*}{$\begin{array}{l}10.54 \\
\mathrm{p}<0.05\end{array}$} \\
\hline Yes & 170 & $68(40)$ & \\
\hline No & 70 & $22(31.42)$ & \\
\hline Don’t know & 228 & $56(24.56)$ & \\
\hline \multicolumn{3}{|c|}{ Drinking habit among siblings/ friends } & \multirow{5}{*}{$\begin{array}{l}16.38 \\
p<0.05\end{array}$} \\
\hline Yes & 117 & $50(42.73)$ & \\
\hline No & 250 & $70(28)$ & \\
\hline I don't have siblings & 18 & $9(50)$ & \\
\hline I don't know & 81 & $16(19.75)$ & \\
\hline \multicolumn{3}{|c|}{ Discussion about ill effects of alcohol at school or home } & \multirow{3}{*}{$\begin{array}{l}3.19 \\
\mathrm{p}<0.05\end{array}$} \\
\hline Yes & 294 & $100(34.01)$ & \\
\hline No & 176 & $46(29.13)$ & \\
\hline \multicolumn{3}{|l|}{ Tobacco use } & \multirow{3}{*}{$\begin{array}{l}44.87 \\
p<0.001\end{array}$} \\
\hline Yes & 62 & $42(67.74)$ & \\
\hline No & 408 & $104(25.49)$ & \\
\hline
\end{tabular}

Table 3: Pattern of alcohol use.

\begin{tabular}{|c|c|c|}
\hline Characteristics & Number & Percentage $(\%)$ \\
\hline \multicolumn{3}{|l|}{ Type of alcohol preference } \\
\hline Beer & 84 & 57.53 \\
\hline Brandy & 9 & 6.1 \\
\hline Whiskey & 4 & 2.74 \\
\hline Rum & 13 & 8.9 \\
\hline Vodka & 8 & 5.4 \\
\hline Others (mixed) & 28 & 19.16 \\
\hline \multicolumn{3}{|l|}{ Usual place of alcohol consumption } \\
\hline Home & 12 & 8.22 \\
\hline Friends home & 30 & 20.55 \\
\hline School & 2 & 1.37 \\
\hline Public place & 102 & 69.86 \\
\hline Usual company for drinking & 120 & 82.19 \\
\hline Friends, Family & 4 & 2.74 \\
\hline New friends & 9 & 6.16 \\
\hline I don't drink as a routine & 12 & 8.22 \\
\hline \multicolumn{3}{|l|}{ Frequency of alcohol use } \\
\hline Monthly once & 66 & 45.52 \\
\hline less than 2-4 times a month & 26 & 17.93 \\
\hline $2-3$ times a week & 7 & 4.83 \\
\hline 4 or more times a week & 11 & 7.59 \\
\hline None of the above & 35 & 24.14 \\
\hline \multicolumn{3}{|l|}{ No. of drinks } \\
\hline 1 or 2 & 103 & 70.55 \\
\hline 3 or 4 & 25 & 17.12 \\
\hline 5 or 6 & 6 & 3.42 \\
\hline 7 or 9 & 4 & 2.74 \\
\hline 10 or more & 8 & 5.48 \\
\hline \multicolumn{3}{|l|}{ Procurement of alcohol } \\
\hline Buy it myself & 47 & 32.19 \\
\hline Give money and ask someone to buy & 34 & 23.29 \\
\hline Get it from friends & 62 & 42.47 \\
\hline Get it from family & 1 & 0.68 \\
\hline Stealing & 1 & 0.68 \\
\hline
\end{tabular}




\section{Problem drinking identification}

On analysis, as per the CAGE Questionnaire, the screening test for problem drinking and potential alcohol problems, 104 out of $146(71.23 \%)$ gets a score of 2 and above. These are the students who have the possibility of alcoholism and should be investigated further for severity of alcohol use (Table 4). For the questions from AUDIT questionnaire, nearly $30 \%$ of the participants had impaired control over drinking almost daily and $17 \%$ had injury or injured someone because of drinking (Table 5).
Apart from CAGE and AUDIT questionnaire, questions were asked to identify problem drinking among the study participants. It showed that $71.92 \% \quad(n=105)$ got into trouble with family or friends, missed school or got into fights $>10$ times in the past 30 days, 35\% $(n=50)$ had lost interest in their hobbies, $22 \%(n=33)$ felt irritated at the usual drinking time especially if alcohol is not available, $30 \%(n=43)$ had the habit of hiding alcohol in unusual places, $17 \%(n=25)$ had withdrawal symptoms and $25 \%$ had developed tolerance.

Table 4: CAGE questionnaire.

\begin{tabular}{|lllll|}
\hline Question & Number & \multicolumn{2}{c|}{ Percentage (\%) } \\
\hline Have you ever felt the need to cut down on your drinking & Yes & No & Yes & No \\
\hline Have people annoyed you by criticizing your drinking? & 712 & 34 & 76.21 & 23.29 \\
\hline Have you felt bad or guilty about your drinking? & 13 & 67 & 53.47 & 46.53 \\
\hline $\begin{array}{l}\text { Have you ever had a drink first thing in the morning to } \\
\text { steady your nerves or get rid of hangover? }\end{array}$ & \multirow{2}{*}{10} & \multirow{2}{*}{136} & 70.54 & 29.45 \\
\hline
\end{tabular}

Table 5: AUDIT questionnaire.

\begin{tabular}{|c|c|c|}
\hline Question & Number & Percentage $(\%)$ \\
\hline \multicolumn{3}{|c|}{ Frequency of impaired control over drinking } \\
\hline Never & 42 & 28.77 \\
\hline Less than monthly & 12 & 8.22 \\
\hline Monthly & 10 & 6.85 \\
\hline Weekly & 35 & 23.97 \\
\hline Daily or almost daily & 47 & 32.19 \\
\hline \multicolumn{3}{|c|}{ Failure to do what expected because of drinking } \\
\hline Never & 90 & 61.64 \\
\hline Less than monthly & 18 & 12.33 \\
\hline Monthly & 10 & 6.85 \\
\hline Weekly & 28 & 19.18 \\
\hline Daily or almost daily & 0 & 0 \\
\hline \multicolumn{3}{|c|}{ Unable to remember what happened night before } \\
\hline Never & 104 & 71.23 \\
\hline Less than monthly & 21 & 14.38 \\
\hline Monthly & 9 & 6.16 \\
\hline Weekly & 12 & 8.22 \\
\hline Daily or almost daily & 0 & 0 \\
\hline \multicolumn{3}{|l|}{ Injured because of drinking } \\
\hline No & 113 & 77.4 \\
\hline Yes, but not in the last year & 8 & 5.48 \\
\hline Yes, during the last year & 25 & 17.12 \\
\hline
\end{tabular}

\section{DISCUSSION}

The objective of this study is to find the prevalence of alcoholism among higher secondary school children and to get an idea about the causative and contributing factors and pattern of alcohol use among them.

The prevalence of alcohol use in this study is $31 \%$ which is quite higher than the previous studies. Most of the available studies on the prevalence of alcoholism were conducted in general population or among college students. Out of the few studies available for school children, the prevalence varies from 4 to $14 \%$. Gunjal et al study of tobacco and alcohol use among students in tribal schools in central India shows the prevalence of alcohol consumption to be $4.07 \%$, which is comparatively lower than our study. ${ }^{6}$ This shows the trend of increase in alcohol consumption which starts even in a younger age group. And this is of serious concern to the society. 
A study conducted in North India by Sorab et al to assess the prevalence of substance use among male college students revealed a prevalence of alcohol consumption as $53.5 \% .^{7}$ This shows that the prevalence further increases in college students and in the general population.

The mean age group during which alcohol was first tried was 16.26 in our study. A study conducted in Karnataka showed the average age as 16.82 years by Padma et al, whereas another study conducted in central India produced the average age as 9.5 years by Sorab et al. ${ }^{7,6}$ The age of initiation of drinking is going down and more young children are getting the habit of alcohol consumption at a very early age.

The reason for first drinking is family occasions and festivals for $66.43 \%$ of the participants while stress is for $15.07 \%$ of them. This is comparable with Dr Tumge Loyi's study in Arunachal Pradesh and Kerala where the reason for first drink was family and religious occasions (74\%) and compulsion by family and friends $(31.1 \%)$ respectively. ${ }^{9}$

Either of the parents was having the habit of alcoholism in $40 \%$ of the participants, which is significant since parental alcoholism plays a major role in the child's habit. However, this is low when compared to $54.5 \%$ parental habit as reported by Padma et al study in Karnataka and $57.4 \%$ parental habit by Sorab et al study in Chandigarh. 8,7

Alcohol consumption among siblings have been noted in $42.73 \%$ which is higher than the response got by Tumge study in Kerala where $10.2 \%$ of the participants had alcohol consuming siblings. ${ }^{9}$

Eighty two percent of students' company for drinking alcohol is friends and the most usual way (42\%) of getting alcohol is through friends. This explains the role of peer pressure in developing the habit of alcohol consumption.

The usual place of alcohol consumption was any public place in $\sim 70 \%$ of the participants, which imply that many children are drinking without the knowledge of their parents. This implies the lack of parental surveillance. It has also been noted that there is less alcohol use in hostel students who had alcoholic parents, due to less accessibility of procuring alcohol as compared to home. This points out the need for strict vigilance to reduce incidence of alcohol usage.

Of the study population, $57 \%$ of the respondents had a preference for beer. $45 \%$ of students drink alcohol at the frequency of monthly once or less and the usual amount of consumption is 1 or 2 drink per day.

Tobacco use was found among $14.28 \%(n=62)$ of the participants. $67 \%$ of the tobacco consumers also consume alcohol which depicts the close association between tobacco and alcohol.
On assessing the problematic drinking, $71.23 \%$ of the students who have scored 2 and above is the sample of the students who needs immediate intervention. About $30 \%$ of the respondents had impaired control over drinking, $17 \%$ had injured someone or had been injured due to the effect of alcohol, $\sim 70 \%$ got into trouble with family or friends, missed school or got into fights more than 10 times in the past 30 days. This clearly shows the social ill effects of alcohol and its impact on children.

Also $35 \%$ had lost interest in their hobbies, $22 \%$ felt irritated at the usual drinking time especially if alcohol is not available, $30 \%$ had the habit of hiding alcohol in unusual places, $17 \%$ had withdrawal symptoms and $25 \%$ had developed tolerance. All these factors prove impending alcoholism. If not educated and treated immediately possibilities of chronic alcoholism and addiction are more likely.

\section{CONCLUSION}

The mean age of initiation of alcohol consumption is decreasing and the number of alcohol consumers is increasing. Steps should be taken to create awareness about alcohol abuse and motivate children to overcome peer group pressure. They need to be distracted to healthy way of lifestyle and trained in stress management.

\section{ACKNOWLEDGEMENTS}

The authors thank Indian Council of Medical Research for rendering support for this project under the Short-Term Studentship 2014 programme.

\section{Funding: No funding sources}

Conflict of interest: None declared

Ethical approval: The study was approved by the Institutional Ethics Committee

\section{REFERENCES}

1. WHO. Global Status Report on Alcohol 2004. Who int N. 2016: 2016.

2. Ramadas K, Sauvaget C, Thomas G, Fayette JM, Thara S, Sankaranarayanan R. Effect of tobacco chewing, tobacco smoking and alcohol on all-cause and cancer mortality: a cohort study from Trivandrum, India. Cancer Epidemiol. 2010;34:405-12.

3. NCD I Global school-based student health survey (GSHS). Available at: https://www.who.int/ncds/ surveillance/gshs/en/. Accessed 14 October 2016.

4. Alcohol Use Disorders Identification Test (AUDIT). Available from https://www.drugabuse.gov/sites/ default/files/files/AUDIT.pdf. Accessed 14 October 2016.

5. Detecting alcoholism. The CAGE questionnaire. Ewing JA. JAMA. 1984;252(14):1905-7.

6. Gunjal Sandeep S, BorleAmod L, NarlawarUday W, Ughade Suresh N, ChaudhariVijaya L, HumneArun 
Y. Tobacco and Alcohol Use in Tribal School students from Central India. 2012;4(11):1852-7.

7. Gupta S, Sarpal SS, Kumar D, Kaur T, Arora S. Prevalence, pattern and familial effects of substance use among the male college students-a north Indian study. J Clin Diagn Res. 2013;7(8):1632-6.

8. Mohanan P, Swain S, Sanah N, Sharma V, Ghosh D. A study on the prevalence of alcohol consumption, tobacco use and sexual behaviour among adolescents in urban areas of the Udupi district, Karnataka, India. Sultan Qaboos University Med J. 2014;14(1):104.
9. Tumge L. Prevalence and patterns of alcohol use among college students: Comparing scenario in Arunachal Pradesh and Kerala (Doctoral dissertation, SCTIMST); 2014.

Cite this article as: Shankareswari S, Jayapriya B, Sandeep K, Lourdu JA. A study on prevalence of alcohol consumption among higher secondary school students in Theni district, Tamil Nadu. Int J Basic Clin Pharmacol 2020;9:226-32. 